\title{
Moros, cristianos y judíos bajo la corteza de un soneto de Góngora a la Mezquita-Catedral de Córdoba
}

\author{
Moors, Christians and Jews under the bark of a sonnet \\ by Góngora to the Cathedral-Mosque of Córdoba
}

Daniel Waissbein

\begin{abstract}
RESUMEN: "Si ya la vista de llorar cansada" no es soneto amoroso, y no invoca en sus tercetos la mansión de campo de una mujer terrenal, de la que el poeta ha sido desterrado, sino la Catedral de Córdoba, dedicada a la Virgen María. Cercano en temática y expresión al más célebre "Oh excelso muro, oh torres coronadas", esconde bajo sus versos una velada tristeza por el sino de quienes construyeron la Mezquita, y por la expulsión de los judíos de España presente en la alusión, tanto en el primer como en el último verso, a su exilio babilónico. Son aspectos que apuntan a la discreta compasión del autor por el destino contemporáneo de ambos pueblos, judío y musulmán.
\end{abstract}

Palabras clave: Mezquita-Catedral, Hagia Sophia, laus urbis, María, agape, moros, judíos.

ABSTRACT: "Si ya la vista de llorar cansada" is not an amorous sonnet, and does not invoke the country mansion of an earthly beauty, from which the poet has been banished. It refers instead, to the Cathedral of Córdoba, dedicated to the Virgin Mary. Close in form and in subject-matter to the more famous "Oh excelso muro, oh torres coronadas", it hides a veiled sadness for the fate of those who built the Mosque, and for the expulsion of the Jews from Spain. This is present in the allusion, both in the first and the last line, to their Babylonian exile. These aspects point to the author's circumspect sympathy for the contemporary destiny of both communities, Jewish and Moslem.

Keywords: Cathedral-Mosque, Hagia Sophia, laus urbis, Mary, agape, Moors, Jews. 
Al peregrino por tu causa vemos
alcázares dejar, donde excedida
de la sublimidad la vista, apela
para su hermosura,
en que la arquitectura
a la gëometría se rebela,
jaspes calzada y pórfidos vestida.

Soledad segunda (665-671)

Ma non sempre a la scorza

Ramo, né in fior, né ' $n$ foglia

Mostra di for sua natural vertude

Petrarca, Rerum vulgarium fragmenta, CXXV, 17-19

Si ia la vista de llorar cansada,

De cosa puede prometer certeza,

Bellíssima es aquella fortaleza

I generosamente edificada.

Palacio es de mi bella celebrada,

Templo de Amor, alcáçar de nobleza,

Nido de el Phenix de maior belleza

Que bate en nuestra edad pluma dorada.

Muro que sojuzgáis el verde llano,

Torres que defendéis el noble muro,

Almenas que a las torres sois corona,

quando de vuestro dueño soberano

Merezcáis veer la celestial persona,

Representadle mi destierro duro ${ }^{1}$.

"Si ya la vista de llorar cansada" ha sido considerado siempre poema amoroso. Como tal aparece en la sección de sonetos amatorios en manuscritos e impresos de la poesía de Góngora, sin excluir el autorizado MS Chacón. Lo confirman, a su vez, los epígrafes que acompañan el texto desde su temprana

\footnotetext{
${ }^{1}$ Cito este soneto por la edición de Biruté Ciplijauskaité (1981: 277), que reproduce el texto del manuscrito Chacón y no indica ninguna variante significativa en los demás códices y ediciones impresas, y modifico los acentos y la puntuación. Me valgo de Jammes (1994) para los versos que reproduzco de Soledades. Cito otras obras de Góngora por la edición de Antonio Carreira (2000 o 2008), quien moderniza ortografía y puntuación, que modifico en unas pocas ocasiones. Abrevio Cov. por Covarrubias (1611), Au. por Autoridades (1726-1737), Cor. por Corominas (1967), DRAE por Diccionario de la Real Academia (1992) y CH por el manuscrito Chacón, seguido, entre paréntesis, de la datación de dicho manuscrito para las distintas composiciones a las que me refiero.
} 
divulgación: "A una casa de campo de una dama" en BNE 4269; "Casa de plazer donde estaua la dama" en el ms. de Manuel Faría y Sousa (BNE 2892); y "A una casa de campo donde estaua una dama a quien celebrava" en la edición Vicuña (1627) (Góngora, 1981: 277-278)². Sus tres primeras estrofas constituirían, sin embargo, como postulo a continuación, una variante, more gongorino, de un género de origen clásico, la descriptio civitatis o laus urbis, variante que podríamos denominar laus aedificii, o laus templi; y la fortaleza, palacio, templo, alcázar o nido en cuestión no sería otro que la Mezquita-Catedral de Córdoba. El soneto nos refiere, asimismo, a quien es dueño soberano (12) de dicha iglesia, y también bella celebrada (5) del poeta, no criatura humana, sino la Virgen María, en su "encarnación" como Virgen de Villaviciosa, en una estatuilla de reducidas dimensiones, que solía exponerse en la iglesia cordobesa por largos periodos, antes de devolverla a su santuario en la sierra cercana.

Pese a su aparente simplicidad, Góngora nos ofrece una composición compleja y rica en matices y alusiones, más de lo que promete a primera vista $(1 \mathrm{y}$ 2). Sorprende por la intensidad y profundidad de su inesperada alusión al pasado de dos de los tres grandes pueblos de España, aspectos que, contemplados desde un horizonte temporal cristiano, el poeta combina con temas en parte similares a los que examino en mi explicación del sentido devocional del soneto "De pura honestidad templo sagrado" (CH 1582). Allí Góngora describe una figura femenina que tampoco corresponde a la mujer amada, como creyeron editores y comentaristas, sino a esta misma escultura de la Virgen, a la que invoca en el terceto final (Waissbein, 2010). La estatuilla de la Virgen de Villaviciosa, por la que Góngora sentía una intensa devoción, precisamente documentada, y señalada con minucia y abundancia de ejemplos por Dámaso Alonso (1964: 33-34), se solía exhibir en el altar principal de la iglesia cordobesa, donde pasó a exponerse en permanencia tras la muerte del poeta (Góngora, 1963: 251).

La Mezquita, debe recordarse, fue dedicada a la Virgen desde la Reconquista, cuando se la transformó en catedral cristiana. Es por tanto su templo, el templo de la Virgen, que el verso 6 llama Templo de Amor. Más específicamente, se la advocó a la asunción de María, y ello importa al sentido y a la

${ }^{2}$ También lo consideran amoroso Salcedo Coronel (1644: 325), su primer comentarista, único en tratarlo por extenso, así como Ernst Brockhaus y Oreste Frattoni (véase nota 9). "Si ya la vista..." fue imitado libremente, en soneto de orientación misógina que hace hincapié en el desengaño moral del "yo" poético, por el poeta antequerano Agustín de Tejada Páez (1567-1635): Si ya mi vista en lágrimas gastada, / puede ver cosas que le den contento, / aquella torre de alto fundamento / es el albergue de mi bella amada. / Torre, soberbia estás y descollada, / desafiando el alto firmamento, / a las nubes te elevas y del viento / te burlas, de segura y confiada. / No te burles del tiempo, ni te eleves / ni estés contenta por el bien que alcanzas / de encerrar dentro en ti mi amada bella; / que aunque nunca el rigor del viento pruebes, / viento son sus palabras y esperanzas, / sus promesas son viento, y viento es ella (Martos Pérez, 2008: 133). 
construcción del soneto, como explico luego, al comentar una pertinente observación de Ernst Brockhaus sobre la estructura ascensional allí presente, de muros a torres y de torres a almenas (véase nota 9). En él, tal como ocurre en "De pura honestidad..." Góngora se sirve de una variante del procedimiento similar al de transposición "a lo divino", pero con signo opuesto, que cabría denominar "a lo profano" (Waissbein, 2010: 114). Lo hace, como siempre, de manera muy suya, invirtiéndolo aquí y en otros sonetos que por dicho motivo tampoco han sido entendidos. Para ello humaniza en parte, o en apariencia, la figura de la Virgen, a la que se dirige como el amante lo haría a su "Señora", donde a los ecos del apelativo tradicional del culto ("Nuestra Señora"), se unen los matices que provienen de los códigos con que en la lírica petrarquista y cortés se invoca a la dama. Tal situación era corriente en la devoción mariana del sur de España, y se inspiraba en tradiciones místicas y religiosas arábigo-andaluzas que confunden lo erótico con lo divino.

La vinculación de Góngora con el medio religioso cordobés se inició muy temprano, por motivos económicos, al recibir órdenes menores que le permitieron ya en 1577, con apenas quince años de edad, gozar de beneficios eclesiásticos cedidos por su tío materno, a cuya ración catedralicia accedería plenamente más tarde (Artigas, 1925: 38). De la obligada familiaridad del joven poeta con el entorno devocional mariano, de fundamental importancia en la catedral cordobesa, dada la advocación de la misma; y de su trascendencia en la vida de don Luis, nos quedan muchos reflejos literarios, no todos debidamente reconocidos. Entre los que sí lo están figuran el soneto a María "Si ociosa no, asistió naturaleza" (CH 1614); los dos que escribió implorándola por la salud de Felipe III, "En vez, Señora, del cristal luciente" y "Esta de flores, cuando no divina" (CH 1619); y letrillas como la dedicada "A la Purificación de Nuestra Señora, ¡Oh qué verás, Carillejo / hoy en el Templo!" (CH 1615) y las dos dirigidas a la Virgen de Villaviciosa, "Serrana que en el Alcor" y "Virgen a quien hoy fiel" (CH 1609), implorándola por la salud de Diego Mardones, obispo de "su" Catedral, la misma que describe nuestro soneto.

Hay empero varios poemas más, que no se han entendido cabalmente hasta hoy, entre los que figura el que aquí tratamos. Constituyen un fiel reflejo de la doble condición de Góngora, clérigo y poeta, inmerso, en los años de su composición, en el medio religioso de su ciudad natal, donde su actividad eclesiástica ejerció mayor influencia sobre su obra literaria de lo que se piensa. Ésta se manifiesta también en otras poesías no marianas, cuyo mensaje religioso o devocional se ha pasado igualmente por alto. Entre ellas el célebre villancico "No son todos ruiseñores", tenido también por composición amatoria, donde Góngora describe, en cambio, aspectos de la procesión anual cordobesa del Corpus, con una referencia clave a un "mejor instrumento" que ha suscitado perplejidad, y al que se le ha buscado siempre un significado erótico, pero que presen- 
ta una patente alusión órfica a la Cruz de Cristo (Waissbein, 2013: 201). La crítica reciente ha descuidado, en general, el aspecto religioso de la poesía gongorina, impulsada por una visión laica que hace excesivo hincapié en el lado anticlerical del poeta y rebaja la importancia de la vertiente opuesta.

Nuestro soneto habría sido escrito en 1594, según Chacón, pero es bien sabido que sus dataciones no son siempre precisas. Como se trata, pienso, de un poema autobiográfico, vinculado con una ausencia de Córdoba, y Góngora no hizo en 1594 ningún largo viaje del que tengamos noticia, es posible que lo haya compuesto poco antes, en relación con su partida hacia Salamanca en misión eclesiástica en agosto del año anterior. Correspondería, entonces, a la ocasión que vio luego al poeta enfermo "en un parasismal sueño profundo" (2), cuando peligró su vida junto al Tormes, y que le obligó a extender su ausencia de Córdoba por cuatro meses, hasta noviembre de 1593 (Artigas, 1925: 74-75). Chacón data igualmente en 1594 los dos célebres sonetos que comentan otras peripecias de ese viaje, "Descaminado, enfermo, peregrino" y "Muerto me lloró el Tormes en su orilla" (del que proviene la última cita), cuyo significado los vincula, como explicaré, al que nos interesa aquí. Lo más probable es que los tres daten de finales de 1593, o poco después ${ }^{3}$.

Por entonces el poeta, que rondaba los 33 años y había recibido las primeras órdenes mayores, sin llegar al sacerdocio, llevaba unos ocho tras suceder a su tío en el pleno ejercicio de su ración del cabildo de la Catedral. Vivía por tanto constreñido a castidad en su conducta pública y declarada, en razón de sus funciones eclesiásticas. Góngora podía, naturalmente, tener un comportamiento diferente, pero disimulado. Se aceptaba que pudiese sentir pasiones amorosas, e inclusive manifestarlas con gran, si no entera, libertad, pero no que confesase abiertamente una relación sexual, que, por el contrario, sí podía insinuar. Lo hace en "Descaminado, enfermo, peregrino" que acaba, de modo famoso y ambiguo: "más le valiera errar en la montaña / que morir de la suerte que yo muero". Allí el verbo, repetido dos veces en el verso final, evoca tal vez, en un segundo sentido, al que tenía entonces, en Italia, el eufemismo piccola morte, presente también en la lírica popular castellana desde varios siglos antes ${ }^{4}$. Importa mucho que la beldad que provocó dicho comentario fuese la anónima

\footnotetext{
${ }^{3}$ Así como un cuarto soneto, igualmente suscitado por el mismo viaje: "Huésped sacro, señor, no peregrino", ausente en Chacón y en todos los manuscritos, salvo el 3358 de la Biblioteca Riccardiana de Florencia, pero impreso y comentado por Salcedo Coronel, que lo halló entre los papeles de Siruela. Es de clara e indudable autoría gongorina, y por fuerza anterior al 19 de setiembre de 1593 cuando murió el destinatario (Góngora, 1981: 572).

${ }^{4}$ No sé que se haya señalado el infrecuente - $\mathrm{y}$ tan efectivo- desdoblamiento de su personaje que el soneto presenta y que nos hace ver que el poeta ha venido refiriéndose a sí mismo en tercera persona hasta el verso 13, cuando salta, con sorpresiva revelación, en el catorce y último, a la primera persona, poniendo así en evidencia su carácter autobiográfico, sea éste pretendido o real: " ... le valiera... / que yo muero".
} 
ventera de un "pastoral albergue mal cubierto" (7); a todas luces la misma que, en el romance autobiográfico "¿No me bastaba el peligro?", que Chacón esta vez data, sí, en 1593, Góngora llama "basilisco mortal /que está su mayor ponzoña/ en su más dulce mirar" (18-20), y que lo condena a muerte" (49).

Importa porque la condición social inferior de la destinataria de los versos permite el atrevimiento, hasta cierto punto, en boca de un futuro sacerdote, pues no mancha el honor de la "homenajeada". Menos lejana de la bella palaciega de nuestro soneto, es una monja - "la bellísima señora"- a quien Góngora corteja humorísticamente en la deliciosa letrilla "Mandadero es el arquero", siempre de 1593 según Chacón (24). En ella, aunque no llega a los extremos del romance recién citado, el poeta mete a Cupido - inada menos! de ... mozo de los mandados (solían ser mozas) del convento de Santa Fe de Toledo (Góngora, 1980: 129-132). Se trata, sin duda, de la misma dama a la que dirige el espléndido soneto atribuido, pero a todas luces de su mano, "Señora doña Luisa de Cardona". El encuentro entre ambos tuvo lugar al regreso del viaje a Salamanca, cuando Góngora pasó por la ciudad imperial. Como vemos don Luis halló, en este periplo de varios meses, ocupación, provechosa o no, primero con una ventera, belleza muy distinta a la dama palaciega que Salcedo quiere ver en nuestro soneto, y luego con otra dama, más cercana a las circunstancias tan especiales de la verdadera destinataria de "Si ya la vista...", imposibilitada de retribuir, al menos en teoría, por su condición monjil, la devoción del poeta. No del todo, empero, pues le quedaban las jaleas y meladas de propia factura que Góngora, vuelto a Córdoba, le solicita "si ausencia por allá no causa olvido" (12). Esta es la razón por la cual el poeta cierra el soneto con un divertido "en sus manos mi espíritu encomiendo" (14), mezclando, como solía en ocasiones, lo sacro y lo profano, pero desde una perspectiva burlesca opuesta a la del soneto que nos ocupa ${ }^{5}$.

Ateniéndonos a la proximidad temporal en la redacción de estos poemas, suponerle a Góngora dos, tres (o más) amores públicamente declarados y simultáneos, o cuasi, platónicos o no, consumados o no, humilde con ventera, intermedio con monja, y elevado con dama palaciega, habría sido, si no en extremo inverosímil, al menos inconveniente para la reputación de ambos amantes. La dama era beldad, además, tan rica y notoria que habitaba de vez en cuando -e interesa que sea de vez en cuando, como veremos- un palacio que era fortaleza de noble muro, generosamente edificada, y por tanto fácilmente identificable. Recordemos que palacio era siempre una mansión suntuosa, en sentido propio "casa de emperador o de rey" (Cov.). Mantener el secreto y salvar así el buen nombre de la dama de alcurnia tan alta que habitaba en

\footnotetext{
${ }^{5}$ Doña Luisa murió en su convento de Toledo pocos meses después, ocasión que Góngora recuerda en el romance "Moriste, ninfa bella" (CH 1594).
} 
palacio, habría sido difícil, pues muchos curiosos se habrían dedicado a buscar y develar su identidad. Pensemos también que de haber existido amoríos, platónicos o carnales, correspondidos o no, entre un eclesiástico que no era siquiera obispo ni abad, con una mujer tan noble y tan rica, no habrían favorecido en absoluto la reputación de ella... Góngora, sabemos, fue persona discreta y se muestra tal en sus versos; debió ser, por ende, amante discreto, y no habría escrito jamás ningún poema que delatase tales amores, pues las disparidades señaladas entre amante y amada volverían ridícula la pretensión de él y la posición de ella.

En nuestro soneto, por otra parte, el poeta no esconde la identidad de la dama, sino que nos indica que quien allí reside en ocasiones es mujer celestial. A Nuestra Señora, emperatriz y reina, digna palaciega, por ende, sí se la podía amar, con apasionada devoción, por humilde que fuese el amador, sin causar ofensa $^{6}$. De la Virgen de Villaviciosa no era el palacio, su Templo de Amor, visto a la distancia en el poema, tampoco la única residencia que poseía. La dama estaba tal vez ausente cuando el poeta escribe el soneto, como parecen indicarlo los versos 12 y 13: "Cuando de vuestro dueño soberano / merezcáis ver la celestial persona", y ello condice con lo que sabemos de la estatuilla, que "vivía" por entonces en su santuario serrano, y solo visitaba esporádicamente su residencia cordobesa (recuérdese el "Serrana que en el alcor" con que Góngora la invoca en la letrilla citada). Pero la explicación puede ser otra, que indicaremos más abajo. Téngase en cuenta que la señora celestial (13) es también soberana (12).

Extraños cumplidos éstos, en los anales de la poesía amorosa, por subidos que fuesen los habituales elogios cortesanos y petrarquistas a la amada. No los usa nunca Petrarca para calificar a Laura, por más que nos diga, cuando explica cómo nació su pasión, que "uno spirto celeste / .... fu quel ch'i vidi", en el soneto "Erano i capei d'oro al aura sparsi"; o que petrarquistas italianos, como Giordano Bruno, refieran a la beltà sovrana de su dama ${ }^{7}$. Ni se prestan celes-

\footnotetext{
6 "Si ya la vista" sigue, al respecto, una larga tradición medieval, religiosa y literaria. Si las monjas se desposaban, con Cristo, los clérigos lo hacían con la madre de Dios. La Virgen, muy exigente por entonces, se mostraba, en ocasiones que Góngora debió conocer, excesivamente celosa y posesiva. Véase la historia del "calonge" de San Cassiano, en Pisa, que relata Berceo en el Milagro XV, "La boda y la Virgen”: Pese a que "ésti amóla mucho más que muchos cristianos / e fazieli servicio de piedes e de manos" ( 7 y 8), ello no satisfizo a la Gloriosa, que le reprochó su traición cuando el canónigo se desposó en dicha iglesia con otra mujer: "Don fol, malastrugado, torpe y enloquido / ... / Assaz eras varón bien casado conmigo / Io mucho te quería como a buen amigo" (41 y 45-46). Como si no bastasen denuestos y reproches, la Virgen obligó al pobre canónigo a escapar del lecho conyugal en la noche de bodas, antes de que las consumase, e hizo que viviese de allí en más "escondido faciendo oración” (83, Berceo: 63 y 64).

${ }^{7}$ En "De voi, o Dame, la beltà sovrana" (9 de la "Iscusazion del Nolano alle più virituose e leggiadre dame" que comienza "De l’Inghilterra o vague ninfe e belle" en De Gli eroici furori).
} 
tial y soberan $(a)$, usados en sentido absoluto, como en nuestro soneto, a calificar a una amante carnal imaginaria, pues el poeta, de haberla inventado, trataría de volverla algo menos sublime y excelsa, por prurito de verisimilitud, tanto más cuanto que aquí no se dirige a ella, y no la invoca, sino que se limita a mencionarla por ser dueña del palacio. Tampoco usó Góngora celestial en otro lugar para referirse a dama de carne y hueso. Celestial es, sin embargo, adjetivo idóneo para calificar a María, en cualquiera de sus apariciones, tal como lo es también, en el verso anterior, la expresión dueño soberano.

El cómputo de las idas y venidas de la estatuilla de la Virgen de Villaviciosa, entre sus estancias en la Mezquita-Catedral y su santuario en la sierra, que registra Cabra, confirma nuestra comprensión del significado preciso de los versos 12 y 13 (1798: passim). Artigas indica, por su parte, que en 1594 Góngora fue encargado por el cabildo catedralicio de acompañar el regreso de la imagen a su ermita en la sierra (1925: 75). Es probable que se trate de la visita de la "dama" a su "palacio" que siguió a la ausencia que refiere el soneto. Está claro entonces que no tenemos, por grande que sea el mutatis mutandis, una historia como la que narra Emmanuel Le Roy Ladurie (1975: passim), cuando las distancias sociales entre la dama y el párroco, ambos habitantes de una pequeña aldea pirenaica, eran menores, y donde la relación amorosa, "familiar" de tan asidua, pero siempre secreta, se veía facilitada por las circunstancias.

Quienes insisten en ver en el poema un contenido amatorio se encuentran, por tanto, ante un serio dilema, aunque no reparen en él, como es el caso de quienes lo comentaron en el siglo pasado: Miguel Artigas (1925: 72-73), Ernst Brockhaus (1935: 40) y Oreste Frattoni (1948: 42). Según Artigas "si hemos de creer alusiones autobiográficas, algunas de las estrofas que [Góngora] escribió en este año [1593], parece que sintió nacer por entonces un nuevo amor o un retoño de su antigua pasión". Cita varios fragmentos de sonetos mencionados arriba: "Muerto me lloró el Tormes..." y "Descaminado, enfermo...", así como del romance contemporáneo "¿No me bastaba el peligro / de una grave enfermedad...?" y añade que "acaso no haya en todos estos encarecimientos más que poética exaltación, cortesana galantería con alguna dama linajuda; pues en otro de sus sonetos amorosos; "Si ya la vista de llorar cansada" de este tiempo, habla de las torres y almenas del palacio de la bella" (ibíd.).

\footnotetext{
También Góngora usa soberana en dos ocasiones, pero para calificar la belleza, limitación fundamental que le da un importe diferente, restringido a una cualidad física y por ende metafórico: "Soberana beldad, valor divino" (6 del soneto "Velero bosque, de árboles poblado", CH 1606) y "de beldad soberana y peregrina" (11 del soneto "Alta esperanza, gloria del estado", $\mathrm{CH}$ 1607). Góngora emplea soberano/a/os/as 34 veces en total en toda su obra, pero solo dos más para referirse a una mujer. Una, pastora soberana, para designar, precisamente, a la Virgen, sintagma que menciono más abajo; otra, ídolo soberano, en la Comedia del Doctor Carlino es, como explica Laura Dolfi, “cita irónica” (Góngora, 1993: 251).
} 
Brockaus lo parafrasea bajo el acápite "Fern von der Geliebten" donde incluye otros dos sonetos de lejanía del objeto amado: "Cuantas al Duero le he negado ausente" (CH 1596) y "En el cristal de tu divina mano" (CH 1609), cuyo tono, muy distinto, refleja la índole diversa de la amada y del amor que los inspira, terreno en éstos, espiritual en aquél. Brockhaus habría debido analizarlo, en cambio, junto a otro soneto entre los más famosos “ $¡ O$ Oh excelso muro, o torres coronadas!" con el que sí presenta, como se verá, esclarecedoras afinidades. El crítico alemán repite las indicaciones de Salcedo relativas a sus tres supuestas fuentes, dos petrarquistas, indudables, que acepto y menciono abajo, y otra, improbable, del soneto 98 de F. M. Molza, "Alma Fenice, che dal sacro nido / Al ciel v'alzate con si salde penne".

Brockhaus (1935: 40) destaca que en el primer terceto Góngora alza la mirada del lector ("hebt der Dicther unseren Blick") del llano, pasando por el muro y las torres hasta sus almenas pero, como Brockhaus desconoce el importe devocional del soneto, no repara que al subir la visión del suelo al cielo, Góngora evoca, en juego alusivo, la ascensión de la Virgen. Ello en razón del nombre del edificio, porque, dedicado a la joven madre judía desde su reconquista en 1236, si bien fue conocido primero como Catedral de María, entre fines del XVI y 1607 "comenzó a denominarse Nuestra Señora de la Asunción”, nombre que mantiene (Recio Mateo, 2005: 139). El soneto alude, en el movimiento ascendente con que guía nuestra propia mirada, a esta dedicación. Un orden similar, de abajo arriba, existe, por igual motivo, sin duda, en la descripción de la estatuilla de María en la Mezquita-Catedral en el soneto "De pura honestidad templo sagrado" (CH1582, Waissbein, 2010).

Frattoni, tercer y último comentarista, se limita a advertir el "aire... de sencillez", así como una "fluidez general" de los versos del soneto, y destaca con razón "la importancia que se atribuye a las enumeraciones" (1948: 43, en verdad 42, con paginación errada) sin reparar en que son todas de índole arquitectónica ni preguntarse por su razón de ser.

Artigas, Brockhaus y Frattoni siguen las pautas ofrecidas por Salcedo, primer comentarista "deste Soneto", y único que los precedió, quien cree poder resolver el dilema... a su manera. Infiere, así, "que le compuso don Luis en nombre de algún señor amigo suyo, a un castillo, o casa de placer en que asistía la dama que celebra. Supone el poeta que la reconoce desde lexos, después de larga ausencia” (1644: 357). Góngora, para Salcedo, se pondría en el lugar de su amigo, y le hablaría, no a la amada, sino al castillo o casa de placer de la amada de su amigo, con la voz del amigo, en su lugar, para decirle a dicho objeto que le hiciere saber a su ilustrísima posesora, cuando ella regresare, que su amigo estaría sufriendo un duro destierro... Algo por demás improbable: no nos consta que Góngora haya escrito jamás poemas amatorios por encargo, ni menos en nombre de terceros, ni en circunstancias similares. Si existiese, la casa de pla- 
cer de Salcedo correspondería a la espléndida casa de campo donde dicha celestial dama iría a solazarse con la naturaleza circundante representada por el verde llano del verso 8 . Lo haría empero, dificultad insalvable, a la manera de un ave fénix que, como sabemos, se eleva en vuelo cuando renace de sus cenizas. Y no una fénix cualquiera - por única que haya sido el ave en la mitología- sino la de mayor belleza. Los superlativos que don Luis habría prodigado a la amiga de su amigo, en este soneto, serían verdaderamente excepcionales...

No veo motivo para afirmar que Góngora escribió "Si ya la vista..." para terceros. Nos refiere, pienso, a su propia persona, y coincide con los datos históricos y biográficos que conocemos y que nos permiten explicar su significado. El ave fénix (7) del poema existe, aunque no es mujer terrenal, y el amor que el "yo" poético siente por ella es intenso, si bien es sobre todo devoción, mas ágape que eros y corresponde al que sabemos que Góngora sentía por la Virgen de Villaviciosa La fortaleza (3), que es palacio (5) y es alcázar (6) existe asimismo, salvo que estos aspectos del edificio están supeditados a otro, fundamental, que Góngora elude nombrar, como casi siempre, invitando así al lector u oyente a buscar "bajo la corteza". Y "bajo la corteza" encontramos la Iglesia Catedral de Córdoba. El poeta lo indica, a su manera, con una perífrasis, cuando nos dice que el palacio es Templo de Amor (6) y nido del fénix (7). Es imprescindible recordar, por otra parte, que la Mezquita de Córdoba, a diferencia de tantas iglesias, tiene muro (9), torres (10) y almenas (11) muy reales, nada metafóricos

Yerra Salcedo, en mi opinión, en referirnos al castillo de la dama. Castillo es palabra que no aparece en el soneto, porque el edificio cordobés que Góngora nos describe, no lo es: tiene muro y torres con almenas, que cuadran con las definiciones contemporáneas de fortaleza (3), palacio (5) y alcázar (6), pero carece de baluartes y de fosos, indispensables a la de castillo ${ }^{8}$. Tampoco acierta, pienso, cuando afirma que el poeta reconoce el edificio, pues si bien es cierto que el "yo" del soneto lo ve desde lexos, los versos no dan ninguna pauta de que ello ocurra, como afirma Salcedo, después de larga ausencia. Me parece más verosímil que indiquen, en cambio, que el poeta se aleja de él y lo mira quizá por última vez antes que lo difumine la distancia u oculte la orografía. En la interpretación que favorezco el poeta no reconoce la fortaleza, pues ha transcurrido poco tiempo desde que la ha abandonado y no se le ha desdibujado en la memoria, sino que la tiene muy presente y no hace mucho que ha dejado

\footnotetext{
${ }^{8}$ Un castillo está cercado de "baluartes, fosos y otras fortificaciones" (Au.) Baluarte es el "reparo fuerte delante de la muralla para resistir a los enemigos y a sus baterías" (Cov.). Góngora no menciona baluartes ni fosos, que tampoco existen en la Mezquita-Catedral. Fortaleza, en cambio, es, simplemente, "cualquier lugar bien flanqueado y defendido" ( $A u$.), lo cual corresponde a esta iglesia.
} 
de verla cuando vuelve a hacerlo, tal vez mientras se aleja de ella, y quizá por última vez en el viaje que emprende. Constata en cambio, con admiración, siempre, su hermosura y el esplendor y magnificencia de su construcción, aquello, precisamente, de lo cual la vista le puede prometer certeza.

Si Góngora —o quienquiera que fuese el "yo" del poema, voz poética impostada o autobiográfica - regresase de su destierro, como supone Salcedo, ello debería ser causa de alegría, no de cansado llanto, a menos que el llanto cesase con la visión beatífica, en el preciso momento que el soneto presenta. ¿Cómo explicar, entonces, que el exilio del amante, que el soneto declara en su último terceto, no acabe con su propio regreso? Sabemos que no acaba, pues el "yo" del poema encomienda a partes del edificio que representen su destierro duro a la dama (14), cuando ella regrese y ellos merez[can] ver [su] celestial persona (13). Merecer, en dicho verso es sinónimo de conseguir, alcanzar o lograr, acepción hoy desusada, según DRAE. No creo tampoco que quien nos habla en el poema estuviese constreñido a un destierro duro (14), que solo consistía en la prohibición de presentarse ante la dama. De ser así, estando ella ausente de su palacio (5) como es el caso, nada le habría impedido a él acercarse a la bellísima ... fortaleza (3), para admirarla mejor. El imperativo representadle dirigido a muro, torres y almenas implica, por otra parte, que la amada no sabe de la ausencia de su servidor, o que se ha olvidado de ella, o no la tiene en cuenta. Inverosímil en una bella, linajuda o no, por cruel o indiferente o desdeñosa que fuese.

Si la dama en cuestión es la Virgen, en cambio, como sus admiradores son legión, es admisible que no atienda siempre con la misma minucia a cuáles andan cerca y cuáles no, por celosa que pueda mostrarse en ocasiones, como la que hemos visto que narra Berceo (nota 6). El imperativo representadle... precedido del cuando merezcáis ver... cobra mayor sentido si al abandonar la fortaleza el poeta no pudo anunciar su partida a la bella celebrada - la imagen de la Virgen - porque la estatuilla, como he indicado, estaba ausente entonces, en su santuario en la sierra. Tampoco habría vuelto ya, y esto se explicaría porque ha transcurrido tan poco tiempo desde la partida de él que es imposible que ella haya regresado desde la ermita donde, en la época, pasaba la mayor parte de sus días. El poeta les encomienda entonces a muro, torres y almenas - las partes del edificio que él ve en ese momento-, que cuando ellos, a su vez, vean a la Virgen volviendo a su palacio, entrando en él, en un futuro indeterminado, le representen su propia ausencia, que ha de durar más que la de ella, su destierro duro, solo de él, que ha empezado ya cuando escribe el soneto. Pero existe otra explicación igualmente posible que, como he indicado, refiero más adelante.

Resulta entonces - y es matiz que lo cambia todo - que quien poetiza no sufre destierro duro por alejarse de la dama, o su imagen, pues vemos que ella no estaba allí entonces, y el poeta no lamenta en sus versos la ausencia de ella, sino que deplora su propia distancia y separación de la espléndida fortaleza 
(palacio, templo, alcázar y nido de ella). Esta distinción, a la que es imprescindible atender - la tristeza del yo poético ante su lejanía del edificio, y no ante su separación de la "bella" que allí reside en ocasiones-, es fundamental, y cambia, como se verá, todo el sentido del soneto. Lo hace, se debe observar, retomando una larga tradición vetero-testamentaria, el recuerdo de la patria durante el destierro, y el lamentarse de la ausencia del lugar amado, que remonta a los Salmos. No sabemos en cambio, pues el soneto no lo explica, hasta tanto no atendemos a lo que implica, lo que haremos en otra sección de este trabajo, si la fortaleza le es tan cara al "yo" del poema porque pertenece a la bella, o por la sola hermosura del edificio, o porque cuando ambos se encuentran allí él puede gozar de la presencia de la beldad amada, o por varias o todas de estas razones, o por ninguna de ellas.

Existen empero indicios que nos permiten concluir de otra manera: "Si ya la vista..." recuerda de cerca otro soneto de ausencia de Córdoba, más bell[o] aún y más justamente celebrad[o] (5), "¡Oh excelso muro, oh torres coronadas...!" (CH 1585), una de las primeras obras maestras de Góngora, si bien carente de cualquier referencia mariana, donde el poeta expresa asimismo su dolor, y donde el llanto, implícito en su primer terceto, surge de la clara alusión bíblica al salmista. Allí Góngora lamenta, junto a las aguas de la Babilonia/Granada, identificada por sus dos ríos Genil y Dauro, el cruel exilio de su Jerusalén/Córdoba. $\mathrm{Al}$ hacerlo se dirige, no a los elementos de un único edificio, como aquí, sino que, en la horma de la laus urbis clásica - continuada por los juglares de la Edad Media, como actividad proficuamente remunerada y floreciente asimismo entre los humanistas italianos (Menéndez Pidal, 1956: 51) — invoca distintas construcciones y características topográficas de su ciudad natal. Lo hace inspirándose, como supone Alonso Asenjo, en la Descriptio Cordubae de mediados del XV de Jerónimo de Córdoba (2005: 140). Utiliza para ello nada menos que siete vocablos que vuelve a mencionar en nuestro soneto, al decirle a su patria que si "tu memoria no fue alimento mío // nunca merezcan mis ausentes ojos / ver tu muro, tus torres y tu río / tu llano y sierra ..." (12-14) ${ }^{9}$.

En esa arquitectura cordobesa, en su muro excelso y en sus torres coronadas, y en esa memoria que alimenta su exilio granadino, aunque el poeta también eluda nombrarla, y ni siquiera, a diferencia de lo que ocurre en "Si ya la vista...", aluda a ella de modo directo, la Mezquita-Catedral no podía menos que ocupar el primer lugar, por su importancia y belleza, y por las funciones

${ }^{9}$ R. O. Jones, que señala la reminiscencia, la limita al versículo 5 del salmo $136 / 137$ "Si oblitus fuero tui Hierusalem, oblivioni detur dextera mea" (Góngora, 1966: 151), y pasa por alto la del primer versículo: "Super flumina Babylonis illic sedimus et flevimus cum recordaremur Sion" aludido por el poeta, con habitual concisión, en la mención de los dos ríos, Dauro/Tigris y Genil/Éufrates. 
que en ella le cabían a Góngora ${ }^{10}$. Las coincidencias entre ambos poemas abarcan, en efecto, tono y procedimiento. Entre los elementos repetidos, por su parte, algunos son piedras angulares en la construcción no solo de la ciudad y del templo, sino de los dos sonetos. El primer verso " $\mathrm{O}$ Oh excelso muro, oh torres coronadas!", anticipa ya dos elementos que volveremos a encontrar al final: "ver tu muro, tus torres y tu río" (13), y que Góngora retoma ocho o nueve años después en "Si ya la vista...". No indica nunca el poeta los nombres de las dos ciudades: Granada (reconocible por sus dos ríos), y Córdoba, que permite identificar el patria del verso 7, repetido en el resonante elogio final "oh patria, oh flor de España" (que traduce el decus Hyspaniae de Jerónimo de Córdoba (fol. 50 r)). Sabemos también que el poeta se refiere a Córdoba por la mención de su fértil llano (7) proverbial en las loas a la ciudad bética, detalle al que volveré, pues el sintagma se modifica levemente en verde llano (9) en nuestro soneto. Ni nombra Góngora a la mezquita tampoco en "Si ya la vista...", siguiendo su invariable costumbre de aludir a lo más importante eludiéndolo, por aquello de intelligenti pauca, tal vez; sino que se limita a describirla: templo (de amor), nido (del fénix de mayor belleza), torres, almenas, muro; y a alabarla: bellísima fortaleza, generosamente edificada.

Hay sin embargo, como veremos a continuación, más coincidencias entre ambos sonetos.

Ya el primer verso del primer cuarteto,

Si ia la vista de llorar cansada

De cosa puede prometer certeza

Bellissima es aquella fortaleza

I generosamente edificada ${ }^{11}$

\footnotetext{
10 Jerónimo de Córdoba, que refiere a la "turris egregia" de la Catedral, considera ésta última "incluso superior a las siete maravillas del mundo", que enumera, y pregunta "quis illa ulterior praecipua reputabat cum in nostra civitate tale templum conspexerit" (“quién las tendrá por mejores después de ver tal templo en nuestra ciudad?", fol. $50 \mathrm{v}$, citado por Alonso Asenjo, 2005: 141). Góngora se referirá al Escorial como "octava maravilla" en otro soneto, también escrito muy probablemente en 1593 y comentado abajo.

${ }^{11}$ Biruté Ciplijauskaité vincula el primer verso al que reza, en el canto XXXII de Ausías March, en traducción de Montemayor, de 1560, "los ojos tristes de llorar cansados" (Góngora, 1981: 278). El posible recuerdo pudo contaminarse con la expresión "la vista cansada, los ojos cansados", corriente en época de Góngora, como lo señala Salcedo (1646: 357). El sintagma reaparece a menudo, con ligeras variantes en su obra primeriza: al comienzo del soneto "Suspiros tristes, lágrimas cansadas" (CH 1582) y en el verso 8 de "Sobre dos urnas de cristal labradas" (CH 1582): "Él, derramando lágrimas cansadas"; así como en los romances "En el caudaloso río" (CH 1581): "Con mis lágrimas cansadas" (48); y "Érase una vieja" (de autoría dudosa): "Lagrimas cansadas" (24). Se trata de poesías de temprana influencia petrarquista; pero la expresión también figura en la letrilla jocosa "¿Qué lleva el señor Esgueva?” (1603): "lleva lágrimas cansadas” (23, con sentido escatológico); y en sentido propio en el soneto "A los campos de Lepe, a las arenas" (CH 1607): “dieron mis ojos lágrimas cansadas" (13).
} 
alude, de entrada, al Salmo 136/137, como el lector descubre retrospectivamente cuando, al llegar al último, conoce por fin el destierro duro del poeta. El primero tiene entonces por misión alertarnos ipero solo en una relectura! $-\mathrm{y}$ las composiciones gongorinas de arte mayor nunca permiten omitirla- a la presencia de un subtexto religioso. En la Biblia el salmista llora su largo destierro. En "Si ya la vista...", en cambio, las lágrimas provienen, como he sugerido, de una separación que acaba de comenzar, que el poeta sabe que será tal vez larga, pero en cualquier caso $d u r[a]$, como lo dice en el último verso. La certeza

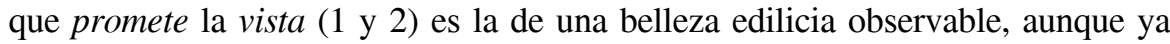
presente en la imaginación y la memoria, como veremos, pero que ahora se constata una vez más. Prometer, en su segunda acepción, que registra $A u$. "vale también asegurar o aseverar alguna cosa". La Catedral de Córdoba es, en efecto, una fortaleza (3) pues fue construida como mezquita fortificada, con una muralla en todo su perímetro, para su defensa de las posibles incursiones que culminaron en la conquista cristiana. Es asimismo, y fuera de toda duda, bellísima (3), y ha sido edificada con la grandiosidad y nobleza que transmite de modo cabal el adverbio generosamente (4).

Existe sin embargo una diferencia notable entre la hermosura de la construcción inicial y la inferioridad patente de las modificaciones y adiciones cristianas, que la dañaron de manera irremediable, reemplazándola en parte con un edificio inferior, como se observa aún hoy, y que Góngora no pudo menos que constatar repetidamente, día tras día, año tras año, en los muchos de su vida de racionero. Salta a la vista, por cansada que esté; aunque el poeta calle, prudentemente, todo comentario y juicio valorativo explícito. El juicio, empero, como los versos dejan traslucir, no pudo menos que existir in pectore. Nos consta, pues se refleja de modo larvado, como lo veremos al examinar otros versos del soneto.

En la esfera teológica, en la que Góngora incurre igualmente, fortaleza es "una de las quatro virtudes Cardinales, que dispone al ánimo para las cosas terribles y amargas" ( $A u$.), la fortitudo latina, virtud que la Virgen encarnó, con preeminencia, en el momento de la crucifixión de Jesús. En el imaginario cristiano María comparte, en alguna medida, las características que el Salmo 45/46 atribuye al Dios de Jacob. ${ }^{12}$ El poeta identifica con ella no solo la imagen de la fortaleza, sino también la del Templo, pues si el edificio es aquí Templo de amor (6), también lo es, en la teología católica, esta mujer judía elevada a la

12 "Deus noster refugium et virtus" en la Vulgata ("Dios es nuestro amparo y nuestra fortale$z a$ " en la edición de la Sagrada Biblia de Nácar y Colunga, 1991). Son palabras que llevaron a Lutero a componer hacia 1530 su célebre himno Ein feste Burg ist unser Gott, que serviría dos siglos más tarde para la cantata coral de Bach del mismo nombre. Góngora pudo o no tener noticia de la composición de Lutero; pero el mismo proceso alegórico pudo llevarlo a aplicar el concepto, con total independencia, no a Dios sino a María. 
dignidad de madre del joven judío convertido en dios cristiano. Góngora lo declara en otro de los sonetos mencionados arriba, cuando la llama, en el primer verso, "De pura honestidad templo sagrado".

Al empezar el segundo cuarteto

5 Palacio es de mi bella celebrada,

Templo de Amor, alcaçar de nobleza

el verso 5 nos aclara que dicha fortaleza es asimismo el palacio de su bella. Celebrada no solo por el poeta, como quería Salcedo, quien restringe el significado a "que celebro" (p. 357), cuando se trata sin duda de un sentido más cercano al de "que celebran muchos" renciar, obsequiar y venerar alguna cosa sagrada o profana, dándole honor y culto" $(A u$.) y se aplica por tanto, con especial preeminencia y aptitud, a María. El palacio es Templo no solo metafórico, por las razones aducidas en el párrafo anterior sino, asimismo, literalmente. Salcedo lo entendió de otro modo:

Y no la llama templo [a esa fortaleza] impropiamente don Luis, porque se dixo assi (según Parrhasio in quaesitis suis. Epist. 57. y lo trae Thomas Dempstero en sus Paralipomenos ad cap.2 Rossini) cualquier lugar cerrado aunque sea profano: Templum est quilibet locus clausus, etiamsi profanus, \& non augurio consecratus. Y M. Ter. Varron lib. 6 de lingua Latina, apoya esto. Curia Hostilia (dize) Templum est, \& tamen sanctum non est. (p. 358).

Nada de esto hacía falta. Góngora no utiliza la palabra en su sentido de construcción profana en ninguna de las 47 lugares señalados por Nuñez Cáceres $^{14}$. Tampoco aquí, cuando escribe Templo de Amor ${ }^{15}$.

El edificio, nos dice el verso, es asimismo un alcázar de nobleza. Alcázar es "nombre arábigo, [que] vale fortaleza, casa fuerte o castillo, casa real y cesárea" (Cov.). También la falsa etimología difundida por entonces, "de $a l$, artículo, y caizar, que en terminación arábiga es caiserum, domus Cesarea", (Cov.)

${ }^{13}$ Góngora lo pone en evidencia, con típico humor, en la letrilla contemporánea "Mandadero es el arquero" ( $\mathrm{CH}$ 1593) que refiere a su visita a Toledo durante el regreso del mismo viaje a Salamanca. Allí la primera mudanza empieza con los versos "Vio una monja celebrada /.../../ cuanto de mil requebrada" (3 y 6).

${ }^{14}$ Sí en sentido jocoso, como, tras una urticaria, en "Iré esta tarde a completas / a ese templo de garduñas / donde colgaré las uñas, / como el cojo las muletas" (5-8) de las redondillas "Ya señoras de mi vida", tituladas por Chacón "A unas monjas, convaleciente de la enfermedad que refiere" (CH 1591).

${ }^{15}$ Góngora volverá a utilizar el sintagma, en plural: "templos de amor", en contexto pagano, en los versos "Deidades ambas divinas / veneradas, en los bosques, / en tantos templos de amor/ cuantos son los cazadores" (vv. 13-16) del romance que dedica en 1607 a la Marquesa de Ayamonte y a su hija, "Donde esclarecidamente", composición de corte mitológico, pues en sus versos "arde algún silvestre dios" (27) y "ofrece el mar las cenizas / de algunos marinos dioses" (31 y 32$)$. 
refuerza dicha acepción ${ }^{16}$. Recordemos que la Virgen es "reina y señora" y corresponde por ende que su alcázar sea de nobleza, digna casa de María, su dueño soberano. La nobleza corresponde a la de su poseedora, pues la Virgen es la más noble entre todas las mujeres ${ }^{17}$. Alcázar, usado como designación para la Mezquita-Catedral tiene también una justificación de vecindad. El de Córdoba, propiamente dicho, le es tan cercano que, vistos a distancia, como es aquí el caso, pueden llegar a confundirse las dos moles en una.

Este segundo cuarteto acaba con dos versos:

7 Nido de el Phenix de maior belleza

Que bate en nuestra edad pluma dorada

que refieren a la Virgen en metáfora de Fénix, imagen tan antigua, y tan anterior a cualquier petrarquismo, que remonta a Lactancio (siglo III), y a Rufino (siglo v) cuando ambos, en los comienzos de nuestra edad destacan la ausencia de concupiscencia y de apareamiento reproductivo que caracterizan a Virgen y ave, y vinculan ambas figuras ${ }^{18}$. Por nuestra edad el poeta se refiere a aquella en que, tras la existencia terrena de la Virgen en las postrimerías de las eras o edades anteriores, la de la antigua Ley y la del paganismo, se la venera ascendida al cielo como el ave fénix.

\footnotetext{
${ }^{16}$ Cor. indica que alcázar proviene “del ár. qasr 'fortaleza', 'palacio' y éste del lat. CASTRUM 'campamento', 'castillo", pero en cambio señala que alcaicería, "lonja a modo de bazar donde tenían los mercaderes sus tiendas” deriva “del ár. qaisariya íd., derivado de Qáisar, nombre que daban los árabes al emperador romano, procedente del lat. CAESAR”, probablemente por haberse empleado en Oriente como alcaicerías edificios de la antigua administración bizantina.

${ }^{17}$ Algo para lo que su condición judía no fue nunca óbice, en la visión contradictoria de los adeptos a la limpieza de sangre. Es ésta una paradoja en la cual los defensores de dicha doctrina no parecen haber meditado, pero que ejercitó a espíritus más sutiles, sensibles, como Góngora, a sus contradicciones, sobre las que no se podía, empero, en su época, indicar que lo eran, sin incurrir en la sospecha de que se lo hacía por interés propio, para avanzar la sangre "sucia" de quienes la objetaban. Véanse, al respecto, en el siglo XV, cuando sí se podían efectuar aún, los comentarios de Juan de Lucena, que defiende con ironía la nobleza del linaje judío, que supera en antigüedad a cualquier otro, en su Diálogo de Vita Beata, como me indica Ángel Gómez Moreno.

${ }^{18}$ Lactancio (Lucius Caelius (o Caecilius) Firmianus, c. 240 - c. 320) en su único poema, De Ave Phoenice, cuya autoría algunos le niegan, y Rufino (Rufinus Aquileiensis o Tyrannius Rufinus, c. 345 - c. 411) en su Expositio Symboli, 9, el primer libro, incidentalmente, impreso en Oxford (en 1478); que puede asimismo ser o no de su cálamo. Es también metáfora corriente en la poesía áurea para referirse a la Virgen, que emplea sor Juana (1976: 66) en las postrimerías del XVII. Su villancico "Primero nocturno", dedicado, precisamente, a la Asunción de María empieza "De tu ligera planta / el curso, Fénix rara, / para, para". Góngora también se sirve de ella en contexto profano, en sintagma muy próximo, en su teatro, donde a las semejanzas con respecto al ave y su nido sigue otra a su vuelo en el verso siguiente, que reemplaza el batir de la pluma dorada por aquélla que argenta el empíreo: "Octava maravilla sois del suelo; Inido de un fénix raro / que argenta el aire con su dulce vuelo" (Isabela, 22-24); y en "Si a Tancredo cada día / el nido yo le fiaba / de la bella fénix mía” (Carlino, 41-43).
} 
Góngora combina la referencia al ave mitológica, en el verso siguiente, con una alusión al cabello rubio de María, en consonancia con la postura petrarquista del soneto, mediante una imagen que recuerda, como vio Salcedo, dos lugares de los Rerum vulgarium fragmenta: el primer verso del soneto CLXXXV: "Questa fenice de l'aurata piuma" y, más aún, los dos iniciales del soneto CCCXXI: "È questo '1 nido in che la mia fenice / Mise l'aurate, et le purpuree penne?" (1646: 358) ${ }^{19}$. A su vez la expresión batir la pluma, evoca la imagen del fénix alzándose para morir y nacer de nuevo, aspecto que convierte al ave en metáfora perfecta para representar la asunción de María, tal como, en otro contexto, representa con igual idoneidad la resurrección de Cristo $^{20}$. También los ángeles, cuando vuelan, baten plumas doradas, como lo recuerda Góngora en otro ejercicio, muy extenso esta vez, de laus urbis, el romance "Ilustre ciudad famosa", de fecha muy cercana (CH 1586). Para alabar en él la hermosura proverbial de sus mujeres, el poeta informa a Granada, a la que describe e invoca - tal como a Córdoba en el soneto en su loor, y su Mezquita-Catedral en "Si ya la vista..." - que ha venido ahora "...a ver de tus bellas damas / los bellos rostros, iguales / a los que en sus hierarquías / las doradas plumas baten" (193-196).

Observamos que el primer terceto:

9 Muro, que sojuzgáis el verde llano, Torres, que defendéis el noble muro Almenas, que a las torres sois corona

consiste en triple invocación, con que el poeta se dirige, en su elogio de la catedral, a tres de sus partes exteriores, aquéllas, precisamente, que constituían el elemento tradicional predominante en todas las laudes urbium: muros, torres y almenas. Gómez Moreno destaca que en uno de los paradigmas del género, "los Mirabilia Urbis Romae, exitosos a la par que breves ... la grandeza de esa ciudad se pone de manifiesto por sus innumerables torres", y cita un pasaje que las destaca en el contexto preciso de su muralla: "Murus urbis Romae habet trecentas sexaginta \& unam turres" (1994: 284). Los tres versos gongorinos, que invocan también las almenas, mencionan además el verde llano de Córdoba, al que no invocan, pues no es parte del edificio. Es, empero, visible, como los otros tres, desde la distancia, efectiva o ideal, en que se el poeta se sitúa al nombrarlos. El muro (9) rodea a la mezquita en todo su perímetro. La palabra

\footnotetext{
${ }^{19}$ Convendría abandonar el dogma, defendido a ultranza por Giulia Poggi, según el cual no existe influencia directa de la poesía de Petrarca sobre Góngora — al menos en el quinquenio inicial de su producción-, sino que esta se manifiesta solo por intermedio de algunos petrarquistas italianos. Se confunde así inspiración con imitación.

20 "Nuestro redentor Jesu Christo y su gloriossísima resurrección, de que [el fénix] parecía pronóstico [...] muchos han formado geroglíficos de la Fénix, aplicándolos a la Resurrección de Nuestro Redentor; y son sin número los que lo han hecho" (Cov. s. v. fénix).
} 
sojuzgáis que lo sigue se justifica, en opinión de Salcedo, "por lo eminente y levantado" del muro del supuesto "castillo" (pág. 358)

Lo es, pero de la Catedral. Muros, torres, almenas no nos permitirían identificar por sí solos fortaleza y ciudad. Lo permiten, en cambio, cuando sabemos que están junto al verde llano, Éste se encuentra a orillas del Guadalquivir, en ambas márgenes, y sobre él se asientan iglesia y urbe. Era proverbialmente verde por su feracidad, que duró mientras los moros lo cultivaron y disminuyó tras la expulsión de éstos, acaecida menos de un par de decenios después de la redacción del poema. Su presencia aquí no deja duda sobre cuál es el palacio que el poeta contempla desde lejos ${ }^{22}$. El color verde corresponde asimismo, motivo que Góngora pudo recordar, a la virtud teologal de la esperanza, que la Virgen encarna. Las torres que defienden el noble muro no nos refieren al alminar, afeado en su conversión en campanario - y quizá por ello Góngora omita su mención - sino a otras, de arquitectura musulmana inalterada, muy numerosas, adosadas al noble muro a intervalos regulares. Son almenadas o, como escribe Góngora, coronadas por almenas. Si de cosa puede prometer certeza este rasgo tan distintivo, por infrecuente en los edificios de culto católico, es que la Mezquita-Catedral es el palacio de [la] bella celebrada.

El terceto final

12 Quando de vuestro dueño soberano

Merezcáis veer la celestial persona, Representadle mi destierro duro.

continúa la invocación del anterior, que remata el imperativo del último verso: representadle. Su objeto gramatical directo, las tres palabras que siguen, con

${ }^{21}$ En "Ilustre ciudad famosa" el poeta llega a Granada para "ver de tus murallas / los soberbios homenajes / tan altos, que casi quieren / hurtalle el oficio a Atlante" (17-20).

${ }^{22}$ En su Descriptio Jerónimo se extasía ante la feracidad del verde llano, que exagera: "Concomitatur autem ad haustrum ciuitati deliciarum quedam frugífera rregio que campinia dicitur, cui tam huberam naturam contulit germinandi virtutem qui si ab incolis tota coleretur vomere Hyspanias omnes suficeret pabulo sustentare" ("sigue a la ciudad por el sur una región fértil de delicias llamada campiña, dotada por la naturaleza de una virtud germinativa tan ubérrima que si sus pobladores la arasen entera bastaría para dar sustento a todas las Españas”, fol. 48 r (citada en latín por Alonso Asenjo, 2005: 140, mi traducción). La importancia que se le otorgaba en la época se refleja en su presencia, reforzada por el calificativo verde, en "Si ya la vista...". En el soneto a Córdoba, como ya se ha visto, el mismo llano no es verde sino fértil; el muro, siempre en singular, es excelso; y las torres no están coronadas por almenas sino "de honor, de majestad, de gallardía". Tal como en "Si ya la vista..." Góngora nos hace ver que "Oh excelso muro..." no ha sido escrito en un lugar precisamente identificable, sino durante el viaje, aquí no de ida, sino de regreso. El poeta, pienso, no está en Granada, pues refiere a las ruinas y despojos de la Alhambra con el adjetivo aquellas, en lugar de estas o aquestas. Tal como en nuestro soneto, Góngora crea un efecto de distancia al escribir ahora "entre aquellas ruinas y despojos", como en el primero “aquella fortaleza". Tampoco aquí ha regresado a Córdoba, pues sus ojos siguen "ausentes” de la "siempre gloriosa patria mía". 
que acaba el poema, mi destierro duro, cierran el círculo abierto por el primer verso, y nos confirman, cancelando la duda que subsiste hasta aquí, que el llanto del verso 1 alude al llanto del salmista. El soneto empieza, y acaba, evocándolo. Dada su colocación, la referencia no podía ser más precisa ni importante. A su vez, en los versos 12 y 13 los adjetivos soberano y celestial, aplicados, respectivamente, a dueño y persona, destacan los atributos que distinguen a la Virgen entre todas las mujeres; dueño, asimismo, continúa el juego petrarquista y cortés, pues podría pensarse en un dominio amoroso, cuando se trata, en verdad, del puramente espiritual. Si soberano significa "el altíssimo y poderosíssimo que es sobre todos" (Cov.), se suele llamar dueño, como explica Au., a "la muger y a las demás cosas del género femenino que tienen dominio en algo, por no llamarlas Dueñas, voz que ya comúnmente se entiende de las dueñas de honor". En uno de sus primeros sonetos, "Cual parece al romper de la mañana" (CH 1582), también siempre considerado amatorio, pero que refiere igualmente a María (Waissbein, en preparación) Góngora llama a la Virgen, siguiendo la convención pastoril, pastora soberana (verso 5). En cuanto a celestial, si bien $A u$. explica que "metaphoricamente se suele llamar así lo que es perfecto, agradable y delicioso", Góngora lo utiliza en sentido propio, o sea "cosa incorpórea, espiritual, que pertenece al cielo", mientras juega, como suele, con el doble sentido.

El último verso del soneto retoma, como he indicado, la referencia al llanto del salmista, que sigue al concepto de visión, la vista del primer verso, ahora bajo la forma infinitiva ver (13). Interesa que muro, torres y almenas no disfruten, como cabría esperar, de la visión, beatífica o no, de su dueño en el preciso momento en que el poeta se dirige a ellos para convertirlos en embajadores de su tristeza. El soneto establece así una limitación temporal terminante: el imperativo final representadle mi destierro duro (14) solo podrá obedecerse cuando muro, torres y almenas merezc[an] ver la celestial persona (13). La explicación reside en que o bien la estatuilla de la Virgen de Villaviciosa no está allí cuando el poeta los apostrofa (sabemos que pasaba largas temporadas en su santuario en la Sierra de Córdoba); o, como podría pensarse igualmente, si la imagen estaba dentro de la Catedral, en la capilla homónima, los muros, torres y almenas no disfrutaban de su visión por ser elementos exteriores de la arquitectura catedralicia. Debían esperar, para ver propiamente a su dueño, que ella entrase o saliese - es decir se encontrase en el ángulo de visión- de los tres elementos personificados en el poema - muros, torres, y almenas- de su palacio, templo, alcázar, nido o fortaleza, extraordinaria serie de sustantivos, ocho, en un poema de solo catorce versos, que denotan claramente por sí solos el interés sobresaliente que el poeta presta a la habitación de la bella celebrada. Idas y venidas ocurrían con relativa frecuencia, pues además de sus viajes a la sierra, se solía pasear en procesión a la pequeña estatua, eminentemente portátil, por 
las calles vecinas a la Mezquita, y por el verde llano circundante. En especial en los momentos de sequía, recurrentes en la región, amén de la procesión anual de Corpus, ayer como hoy. (Waissbein, 2013: passim).

No abundan, en la obra gongorina, poemas que loen la Catedral cordobe$\mathrm{sa}^{23}$. Sorprende, dado el amor que el poeta profesó por su patria, y más cuando pensamos en la hermosura del edificio en el que Góngora pasó gran parte de su vida activa. Nuestra perplejidad ante dicho silencio aumenta cuando recordamos los maravillosos versos en alabanza de otras iglesias, como la catedral de Granada, en el romance "Ilustre ciudad a famosa", la de Toledo en su comedia Isabela, o inclusive los versos tanto menos entusiastas, de hiperbólica frialdad, con que el poeta critica al monasterio del Escorial, bajo la falsa apariencia del elogio, en el soneto "Sacros, altos, dorados capiteles". Sin embargo le cabe al templo de Córdoba en el imaginario cristiano una posición muy especial, similar, pero de sentido opuesto, a Hagia Sophia en Constantinopla, de algunos de cuyos aspectos comunes, al menos, alguien siempre tan informado como Góngora no pudo no tener noticia. Ambos templos, que tienen tanto en común, responden, con insuperable esplendor, a las exigencias arquitectónicas y decorativas respectivas de las dos religiones más populosas, y comparten una historia excepcional, en que la conquista por las armas llevó, en centurias anteriores, a la inflexión del culto que en ambos se celebraba. Lo hicieron, empero, con signo invertido: del cristianismo al islam en aquella situada en el extremo oriental del Mediterráneo, y del credo musulmán al católico en la otra, ubicada en el confín occidental. Ambos edificios reúnen, asimismo, rasgos artísticos de desusada importancia, monumentalidad y belleza, y si en Córdoba priman los musulmanes, que fueron también, cronológicamente, los iniciales ${ }^{24}$, en Constantinopla ocurre lo contrario.

Es notable y es llamativo que Góngora manifieste un persistente silencio en todo lo que atañe al tema. Los silencios gongorinos, en todo caso, más interesantes en él que en otros poetas de su tiempo, porque cargados a menudo de significado, no siempre son absolutos, y es indispensable indagarlos, con los pocos instrumentos que el poeta nos brinda, cuando los interrumpen, como en

${ }^{23}$ Existe una probable alusión en el romance jocoso "Ahora que estoy despacio" ( $\mathrm{CH}$ 1582, Carreira i1588?) donde escribe "en el coro de mi aldea / cantaba mis aleluyas" (11 y 12). Hay otra referencia, ya indicada, en el soneto a Córdoba, cuyo primer verso "O excelso muro, o torres coronadas", menciona elementos arquitectónicos que corresponden tanto a la Catedral como al alcázar y a la muralla de la ciudad. De cualquier modo, aún si tomamos en cuenta nuestro soneto, donde el tratamiento del tema es más extenso, debemos admitir que el silencio gongorino al respecto, tal como otros notables silencios o elusiones, da pábilo a que nos preguntemos por los motivos que lo(s) suscitaron.

${ }^{24}$ En el edificio conservado y visible, no en los cimientos paleocristianos de los que Góngora bien pudo tener escasa o ninguna noticia. 
"Si ya la vista..." breves atisbos de una realidad diferente, a la que debe acceder el crítico para comprender el pensamiento, en ocasiones asaz hermético, de don Luis. No puedo, por ende, reclamar igual crédito para las consideraciones que haré a continuación, del que creo deberse a lo ya expuesto. Admito la índole especulativa de lo que diré a partir de este momento, pero sería escapar a mi obligación de lector y de crítico el omitir hacerlo ${ }^{25}$.

En la Mezquita-Catedral la presencia de lo islámico, en expresión de supremo refinamiento estético, debió contar mucho para nuestro racionero, poeta genial, sensible como pocos a la belleza. Belleza ofrecida aquí, además, a la observación repetida, continuada y precisa que no pudo menos que prodigarle durante sus largos años de diario quehacer en ella. Góngora no pudo no saber que sus devociones ocupaban el marco dejado por un pasado religioso distinto, el islámico, cercano en el tiempo, y proveniente, al igual que el cristianismo, del monoteísmo judío. Ello debió suscitar luces y sombras en sus cavilaciones, necesariamente silentes, dadas las restricciones sociales, políticas y religiosas de la época, luces y sombras sobre las que la crítica moderna, reconfortada en su pereza por la ausencia de indicios explícitos, no se ha siquiera interrogado. Descuenta en cambio, erradamente, que achacarle tal inteligencia y sensibilidad a un escritor de los siglos áureos, sería cometer imperdonable anacronismo. No es siempre así, y no lo es para nuestro poeta, cuya modernidad asombra. El silencio del vate, al respecto, bien pudiera deberse a discreción y prudencia, pues habría podido costarle muy caro manifestar sus propias ideas. Hacer tabla rasa de dicha situación y suponer con porfía que tales cavilaciones, con sus luces y sombras, no existieron - como si Góngora no pensase y no viese aquello que era patente- porque no las encontramos expresadas en blanco y negro, con todas sus letras, en lugar de examinar los indicios que la poesía del cordobés nos ofrece, es adoptar la táctica del avestruz.

Gongoristas hay en nuestros días, y no de los menos conocidos, que no solo mantienen tal actitud, sino que intentan imponerla. Reflejan, al hacerlo, los grandes males de la historia, lejana y reciente, de España, en los que quedan atrapados. Góngora sí supo, gracias a su genialidad, escapar a ellos, como lo muestran sus versos de manera velada, para no poner en peligro vida y obra. Algunos indicios tenemos, sí, y debemos atender a ellos. No más, estrictamente, pero no menos. No hacerlo, por prejuicio, desidia, indiferencia, desatención,

${ }^{25}$ Algo que Góngora (2000: II, 297) supo también explicar mejor que nadie en su Respuesta: "Demás que como el fin del entendimiento es hacer presa en verdades (...) en tanto quedará más deleitado en cuanto, obligándole a la especulación por la oscuridad de la obra, fuere hallando debajo de las sombras de la obscuridad asimilaciones a su concepto". Si bien lo escribió en defensa de sus Soledades, se aplica, naturalmente, a toda su obra. Aunque Carreira pone en tela de juicio la autenticidad de esta carta, dudo que hubiese, entre sus defensores, salvando tal vez al Abad de Rute, escritor capaz de ella. 
temor $\mathrm{u}$, horribile dictu, racismo, nos vuelve culpables de una grave carencia y cómplices de un silencio que ha durado demasiado.

En contraste con los esplendores granadinos o toledanos, ante los que Góngora no ocultó su maravillada sensibilidad, es comprensible en las circunstancias su alabanza menos directa de cuanto atañe al pasado tan conflictivo de la Catedral cordobesa. Qué reservas pudo inspirarle su historia es algo que nunca sabremos con certeza. Un primer indicio, empero, de que no debió compartir la visión triunfalista de un catolicismo impuesto a sangre y fuego en Andalucía nos lo sugiere el que el poeta se permitiese, en su ya citado romance en loor de Granada, contra lo habitual en el género, pero de manera sin duda coherente con su sentir profundo, detenerse en algunas sombras — de evocación menos delicada que las que silencia en relación con la Mezquita cordobesa- que se destacan por constituir el único aspecto negativo del largo poema. Ellas lo apartan del elogio a ultranza, habitual en las descriptiones o laudes urbis, que interrumpe para presentarnos, con relampagueante brevedad, en apenas cuatro de sus 236 versos, con un solo adjetivo, un testimonio de su pesar: “...tu Albaicín, castigo / de rebeldes voluntades / cuerpo vivo en otro tiempo / ya lastimoso cadáver" ("Ilustre ciudad famosa", 145-148).

También en nuestro soneto existe un eco, tenue y disimulado, pero que colora todo su significado, de dichas ideas y sentimientos ${ }^{26}$. Se manifiesta en la evocación, no por implícita menos presente, del "Romance de Abenámar y el rey don Juan", que debió volver tantas veces a la memoria de Góngora cuando contemplaba su entorno mientras cumplía con sus deberes eclesiásticos en la Catedral, y hubo de servirle como trasfondo fértil de ideas y de sentimientos que luego cristalizarían en su poesía. Los versos que debió recordar, y le ofrecieron tal vez el impulso poético inicial para componer "Si ya la vista...", presentan una escena similar a la que abre el soneto, la de magníficos edificios vistos en lejanía, aunque de identificación inicialmente incierta:

\author{
¿Qué castillos son aquellos? \\ ¡Altos son y relucían!: \\ El Alhambra era, señor, \\ y la otra la Mezquita; \\ los otros los Alixares, \\ labrados a maravilla. \\ El moro que los labraba ${ }^{27} \ldots$
}

\footnotetext{
${ }^{26}$ El largo "discurso" en las Soledades contra la codicia que, en opinión del "político serrano" que lo pronuncia, inspiró exclusivamente las navegaciones de descubrimiento y conquista, nos permite saber que Góngora no compartía la visión exaltadora de un catolicismo triunfante por las armas en América (I, 366-502).

${ }^{27}$ Cuando Góngora denomina fortaleza a la mezquita de Córdoba sigue también el precedente del romance, que llama castillo, con o sin estricta justificación, a la de Granada.
} 
También aquí, a la duda inicial, que motiva la pregunta del rey moro, pregunta ausente en "Si ya la vista...", sigue la certeza de la identificación. En el romance ésta proviene del interlocutor mientras que en el soneto, en cambio, un único "yo", que dialoga consigo mismo, responde a su propia duda. y afirma que si de algo tiene certeza, es tanto de la hermosura como de la identidad del edificio que contempla en la lejanía, y de la de su dueña. El paralelo se establece entonces entre castillo moro (Alhambra) de rey moro, con su mezquita, y fortaleza y palacio moro de "reina" judía (la Virgen), devenido, por ser de ella, templo de amor cristiano.

En su poesía Góngora se entrega a veces, con talento e inteligencia excepcionales, a un juego creativo, sorprendente por lo inesperado, basado en composiciones populares o cultas, entre las españolas e italianas y clásicas, a las que recuerda, repitiéndolas, o modificándolas, y que marcan en ocasiones el punto de arranque e ímpetu inicial de su propio componer ${ }^{28}$. Es lo que ocurre también en "Si ya la vista...", que nos informa indirectamente, sin nombrarla, como en respuesta a una pregunta implícita, similar a la que formula el rey don Juan en el romance: “QQué castillos son aquéllos?”, que bellísima es aquella fortaleza, indicación muy parcial, que solo sumada a otros indicios que el soneto nos va proporcionando en la medida justa, nos permite identificarla. En paralelo, el romance nos ofrece asimismo una evocación de los Alijares de Granada, labrados a maravilla, tal como la fortaleza que Góngora nos describe y luego invoca, fue generosamente edificada (4). Si bien, a diferencia de Abenámar, que lo declara todo a su interlocutor, o de Fray Luis en "iQué descansada vida...!", cuando incorpora una explícita alabanza al constructor del edificio en la descripción del "dorado techo / .... Fabricado / del sabio moro, en jaspes sustentado", nuestro poeta es como siempre más económico en el elogio y la referencia. Góngora debió recordar empero los versos de Luis de León, pese a que no circularon en letras de molde hasta que Quevedo los dio a la imprenta en 1631, si bien alguna versión manuscrita hubo de llegar a sus manos, como sabemos que llegó a las de Cervantes ${ }^{29}$. Lo indudable es que Góngora nos deja,

${ }^{28}$ Piénsese, por ejemplo, en la letrilla que comienza "No son todos ruiseñores / los que cantan entre las flores", en el recuerdo de los versos "Entre las rosas e flores / cantaban los ruiseñores / las calandrias y otras aves" (16-18) del "Sueño" de Cristóbal de Castillejo, y la "respuesta" creadora a la que dan lugar, que el poeta indica al empezar y que desarrolla todo a la largo de la espléndida letrilla (Waissbein, 2013: 159).

${ }^{29}$ Debo estas precisiones, que agradezco, a Terence O’Reilly. Indudable recuerdo del mismo verso de Fray Luis y prueba de que Góngora lo conoció sino en 1593 al menos dos décadas más tarde, es el que encontramos en Soledad II (véase el epígrafe). Góngora pone allí a su peregrino, desterrado, al igual que el "yo" de nuestro soneto de un espléndido edificio, pero en el que "la arquitectura / a la gëometría se rebela / jaspes calzada / y pórfidos vestida” (669-671). En jaspes sustentado el palacio que describe Fray Luis, jaspes calzad[o] el de Soledades, eco y no coincidencia fortuita. Los versos "A mí una pobrecilla / mesa, de amable paz bien abastada / me 
como suele, siguiendo el método elusivo y alusivo que lo caracteriza, la tarea de descubrir la identidad de la construcción a la que nos remite. Y cuando nos recuerda cómo fue edificada, nos deja asimismo la tarea de pensar, siguiendo los indicios que nos brinda la presencia implícita de Abenámar y también del poema de Luis de León, si no en el sabio moro que la fabricó, en el romance, o en el moro que la labraba en la oda, en los moros que la edificaron generosamente en su soneto.

Góngora fue, sin embargo, tanto más explícito en identificar el objeto de su aparente alabanza en otra poesía que ya hemos mencionado, dirigida igualmente a un templo, pero muy diferente y recién construido, al que también invoca: el Escorial en el soneto "Sacros, altos, dorados capiteles". Sabemos ahora, gracias a la perspicacia de Ángel Luján Atienza (2005), que, in cauda venenum, el supuesto encomio no es tal. Chacón lo fecha en 1609, pero es por fuerza muy anterior, pues en su último verso desea, con dudosa sinceridad, larga vida a Felipe II, quien murió en 1598. Debió componerse por ende en fecha muy cercana a la de nuestro poema, probablemente en el mismo año de 1593, como supone Jammes, cuando Góngora visitó el Palacio (1967: 263). Describe allí el "templo... / que al mayor mártir de los españoles / erigió el mayor rey de los fieles" (6-8), cuya discutible hermosura señala escuetamente, con sospechosa grandilocuencia, en "la beldad desta Octava Maravilla" (13). Son, precisamente, las palabras que, como se recordará, Jerónimo aplicaba con mayor justificación a la Mezquita-Catedral, en su Descriptio Cordubae (véase nota 12) y pueden estar sarcásticamente evocadas aquí. Nos remiten, por supuesto, al templo que erigió, nos dice el poeta, con oxímoron que esconde otra patente ironía, la "religiosa grandeza / del Monarca" (8-9). Góngora omite mencionar a Felipe por su nombre, si bien, acudiendo nuevamente al Antiguo Testamento, cuya memoria siempre fue alimento [suyo], lo llama en cambio "Salomón Segundo"30".

Con el recuerdo del monarca judío el poeta acaba su composición, aludiendo, mediante la evocación del rey proverbialmente sabio que lo construyó, al Templo por antonomasia, único con el cual el Escorial sería digno de compararse. Ése, como los versos nos obligan a entender, fue para Góngora el Templo de Jerusalén, cuya referencia en el soneto dignificaría y exaltaría al Escorial. Lo exalta empero solo en apariencia, dado el contexto de ominosas y negativas valoraciones. Los versos implican, asimismo, si pensamos en el destino que le cupo al Templo salomónico, que Góngora contempla la posible futu-

\footnotetext{
baste..." (71-73), del mismo poema de Fray Luis han sido señalados recientemente por Robert Jammes como posible fuente de "que yo en mi pobre mesilla / quiero más una morcilla" (13 y 14 de la letrilla Ándeme yo caliente, 2011: 20).

${ }^{30}$ También lo denomina así Covarrubias, que comenta "la grandeza deste segundo templo de Salomón”, quizá influido por este soneto, aunque tal vez fuese alabanza tópica que Góngora pudo iniciar o retomar (1611: 545).
} 
ra destrucción del soberbio monasterio filipino, como reacción, tal vez, a la arrogante opresión que simboliza. La formulación solapada de dicho deseo es tanto más probable cuanto que el escritor la insinúa desde el principio del soneto, al dirigirse a los capiteles del Escorial, en un procedimiento paralelo al que utiliza en "Si ya la vista...", donde también invoca las partes del palacio de la bella, si bien con una valoración antitética, exaltante allí, ominosa aquí. Consiste en anunciarles que "Febo os teme por más lucientes soles / y el cielo por gigantes más crüeles" (3 y 4), gigantes cuyo nefasto sino mitológico, como repara Luján Atienza, es harto conocido (2005: 69). Dicha declaración, ya en el primer cuarteto, instala de entrada en la mente del lector el mensaje de posible destrucción, augurio que refuerza, finalmente, la alusión al templo de Salomón, con la que el soneto acaba. Grandiosidad y magnificencia del Escorial evocan a su vez las formas del dominio de un príncipe, "cuya diestra real al Nuevo Mundo / abrevia, y el oriente se le humilla" como nos recuerda el primer terceto $(10 \text { y } 11)^{31}$.

Todo ello por más que Góngora, en versos signados por todas las contradicciones que Luján Atienza desentraña muy hábilmente (ibíd.), exprese con falsa piedad, en el contrapunto que se instala entre lo que los vocablos parecen decir y lo que significan en verdad, el deseo de que "perdone el tiempo / lisonjee la parca" (12 y13) tanto al Escorial como a "los años", (14) de su hacedor. En la referencia al constructor del Templo que "erigió el mayor rey de los fieles" (4), llamado luego "Salomón segundo" — las dos palabras con que el soneto acaba - aparece la evocación indirecta de Jerusalén, por estar el Templo construido por Salomón en ella. El recuerdo de la ciudad santa se anuncia asimismo en el soneto en loor de Córdoba, en las señaladas referencias a los Salmos, tal como lo hace en el romance a Granada ${ }^{32}$. Como vemos también la falsa loa del Escorial concluye con la evocación implícita de Jerusalén.

Es la misma que le trae al poeta la memoria del destierro de quienes abandonaron y lloran la ciudad de Israel en "Si ya la vista...". Con este exilio, que equi-

\footnotetext{
${ }^{31}$ Aquí abrevia tiene las connotaciones, creo, de 'oprime'. Au. explica que abreviar "se toma algunas veces por detener, contener, y limitar, suspendiendo la acción con que uno puede, o es capaz de obrar"; y ofrece, como ilustración del sentido un ejemplo tomado de la canción "De la toma de Larache" ("En roscas de cristal serpiente breve", CH 1611, Carreira 1610) donde los tres versos citados presentan idéntica construcción: "vuestras banderas nos lo dicen, puesto / duro yugo a los términos del día / en los mundos que abrevia tanta diestra" (71-73). Abreviar aparece a mediados del siglo XIII y deriva de breve. Breves eran las letras apostólicas, bulas o buletos, que se despachaban y escribían sin las formalidades jurídicas, y se conocía a quien las emitía con el nombre de abreviador. (Cov.) Felipe II y III gobernaban el mundo mediante papeles o pergaminos similares. Góngora, como tantas veces, juega con ambos significados, el "aparente" y el "verdadero". Carreira anota "abrevia: 'reúne, sujeta"” (Góngora, 2009: 156).

${ }^{32}$ Góngora evoca el Templo de los judíos en "Ilustre ciudad famosa", también para elogiar la catedral de Granada, el "sagrado templo" al que, con tono de exageración humorística que despunta en otras partes del romance, augura más fama que "el de Salomón, aunque eran / sus piedras rubios metales / marfil y cedro, sus puertas / plata fina, sus umbrales" (85-88).
} 
para al suyo de la Mezquita-Catedral, su "yo" poético se identifica, y por ende también con los judíos desterrados de Jerusalén y, muchos siglos después, en 1492, de España, Lo hace tanto al comenzar, cansado ya de llorar su ausencia de la Mezquita-Catedral, en verso donde su relación con la iglesia de Córdoba reviste las características que definen la relación de los judíos con su Templo de Jerusalén, como al acabar, cuando llama a su alejamiento del mismo, destierro duro. Las mismas consideraciones que he señalado en relación con la actitud del poeta hacia los judíos se aplican también, a mi entender, a la visión que Góngora nos ofrece de los moros que, si bien eran tolerados todavía en España a fines del XVI, perdieron tras su derrota militar el espléndido templo que habían edificado generosamente tres siglos antes. Góngora nos transmite así, mediante este acercamiento circunspecto a los dos pueblos oprimidos de España, la verdad primera y última que el soneto expresa, por alejada que parezca, a primera vista, de llorar cansada, del tema que trata ostensiblemente, para sorpresa del distraído lector: su identificación, en situaciones que no especifica pero que nos da a entender, con los musulmanes vencidos, y con el pueblo de Israel del que muchos de sus antepasados, lo sabemos hoy de modo irrefutable, formaron parte ${ }^{33}$.

\section{BIBLIOGRAFÍA}

Alonso, Dámaso (1964): “Algunas novedades para la biografía de Góngora”, en Frank Pierce y Cyril A. Jones (eds.), Actas del primer congreso internacional de hispanistas (Oxford, 6-11 de septiembre de 1962), Oxford, Dolphin, pp. 25-46.

Alonso Asenjo, Julio (2005): "Sin par loor de Córdoba por Góngora”, Quaderns de filología, X, pp. 133-154.

Artigas, Miguel (1925): Don Luis de Góngora y Argote. Biografía y estudio crítico, Madrid, Tipografía de la Revista de Archivos.

${ }^{33}$ No se ha estudiado aún la presencia, implícita o declarada, del Antiguo Testamento en la obra de Góngora, que dará sorprendentes dividendos. Recuérdese que el poeta escribe, en frase ambigua, en su respuesta a la "Carta que le escribieron en razón de las Soledades, sin firma" (2008: II, 295), "a mí me corren muchas obligaciones de saber poco dél [el Testamento Viejo] por naturaleza y por oficio" (p. 298). Se trata de otra ironía gongorina más, donde el sintagma poco, acumula tres niveles de significado contradictorios, pues en sentido propio equivale a cosa, o algo, y en el sentido que le impone evitar esa misma "alabanza propia, que siempre fue aborrecida" - declaración con que acaba el párrafo- equivale a mucho. Pero a la vez, por las dudas, poco equivale a poco, por razones, de nuevo, políticamente correctas. Sabemos muy bien cuál era el oficio que obligaba a Góngora a saber poco/mucho del Antiguo Testamento, pero ¿qué entendería el poeta por esa naturaleza suya, a la que refiere también? Bien podría ser que el poco de la frase citada difiera en su significado según se aplique a oficio o a naturaleza. Estos tal vez lo obligasen a saber de ese "Testamento Viejo", poco en el sentido de poco el primero (su oficio), y poco, en el sentido de algo, que, modestia aparte debía ser mucho, la segunda (su naturaleza). Son puntos que requieren exploración, tal como el carácter, apócrifo, en el que descreo, o no, de la "Carta". Para la ascendencia judeoconversa de Góngora, véanse las sorprendentes conclusiones a las que ha llegado Enrique Soria Mesa (2013: 415-433). 
Berceo, Gonzalo de (1961): Milagros de Nuestra Señora, Madrid, Espasa-Calpe.

Brockhaus, Ernst (1935): Góngoras Sonettendichtung, Bochum, Heinrich Pöppinghaus.

Bruno, Giordano (1585): De gli eroici furori, Paris, Antonio Baio.

Cabra, Gerónymo Josef de (1798): Memorias antiguas y modernas de la invención, traslaciones y milagros de la prodigiosa imagen de María Santíssima de Villa-Viciosa, que se venera en la santa Iglesia Catedral de esta Ciudad de Córdoba, Recogidas, Ordenadas e Ilustradas por el R. P. Fr Gerómino Josef de Cabra, Córdoba, Luis de Ramos y Coria.

Corominas, Joan y José Antonio Pascual (1980-1991): Diccionario crítico-etimológico castellano e hispánico, 6 vols., Madrid, Gredos.

Covarrubias Horozco, Sebastián (1977 [1611]): Tesoro de la Lengua Castellana o Española, ed. facsímil, Madrid, Ediciones Turner.

Frattoni, Orestes (1948): Ensayo para la historia del soneto en Góngora, Buenos Aires, Universidad de Buenos Aires.

Gómez Moreno, Ángel (1994): "Mérida y la laus urbis", en España y la Italia de los humanistas, Madrid, Gredos, pp. 282-295.

Góngora y Argote, Luis de (1963): Letrillas, Robert Jammes (ed. crít.), Paris, Ediciones HispanoAmericanas.

Góngora y Argote, Luis de (1966): Poems of Góngora, selected, introduced and annotated by R. O. Jones, Cambridge, Cambridge University Press.

Góngora y Argote, Luis de (1980): Letrillas, Robert Jammes (ed.), Madrid, Clásicos Castalia.

Góngora y Argote, Luis de (1981): Sonetos, Biruté Ciplijauskaité (ed. crít.), Madison, Hispanic Seminar of Medieval Studies.

Góngora y Argote, Luis de (1993): Teatro completo, Laura Dolfi (ed.), Madrid, Cátedra.

Góngora y Argote, Luis de (1998): Romances, Antonio Carreira (ed. crít.), 4 vols., Barcelona, Quaderns Crema.

Góngora y Argote, Luis de (2000): Obras completas, II. Las firmezas de Isabela, El doctor Carlino, Comedia Venatoria, Epistolario, Antonio Carreira (ed.), Madrid, Fundación José Antonio de Castro.

Góngora y Argote, Luis de (2008): Obras completas, I. Poemas de autoría segura. Poemas de autenticidad probable, Antonio Carreira (ed.), $2^{\mathrm{a}}$ ed., Madrid, Fundación José Antonio de Castro.

Góngora y Argote, Luis de (2009): Antología poética, Antonio Carreira (ed.), Crítica, Barcelona.

Jammes, Robert (1967): Études sur l'oeuvre poétique de don Luis de Góngora y Argote, Bordeaux, Institut d'Études Ibériques et Ibéro-Américaines de l'Université de Bordeaux.

Jammes, Robert (2011): "Góngora en el espacio y en el tiempo (1609-1615)", en Begoña López Bueno (ed.), El poeta Soledad, Góngora 1609-1615, Zaragoza, Prensas Universitarias de Zaragoza, pp. 11-18.

Juana Inés de la Cruz, Sor (1976): Obras selectas, prólogo, selección y notas de Georgina Sabat de Rivers y Elías. L. Rivers, Barcelona, Noguer.

Le Roy Ladurie, Emmanuel (1975): Montaillou, village occitan de 1294 à 1324, Paris, Gallimard.

Lida de Malkiel, María Rosa (1975 [1961]): "El hilo narrativo de las Soledades", en La tradición clásica en España, Barcelona, Ariel, pp. 241-252.

Lida de Malkiel, María Rosa (1977): "La ciudad, tema poético de tono juglaresco en el Cancionero de Baena", en Estudios sobre la literatura española del siglo XV, Madrid, Porrúa Turanzas, pp. 333-338.

Luján Atienza, Ángel Luis (2003): ““Malhaya el que en señores idolatra”. Las formas de la poesía y el poder”, en Martín Muelas Herráiz y Juan José Gómez Brihuega (coords.), Leer y entender la poesía. Poesía y poder, Cuenca, Universidad de Castilla-La Mancha, pp. 49-72.

Martos Pérez, María D. (2008): La obra poética de A. de Tejada Páez: estudio y edición, tesis doctoral, Málaga, Universidad de Málaga <http://www.biblioteca.uma.es/bbldoc/tesisuma/ 17735580.pdf>. 
Menéndez Pidal, Ramón (1956): Poesía juglaresca y juglares, 4ª ed., Madrid, Austral, EspasaCalpe.

Nácar Fuster, Eloino y Alberto Colunga Cueto (eds.) (1991): Sagrada Biblia. Versión directa de las lenguas originales, $50^{\mathrm{a}}$ ed., Madrid, BAC.

Nieto Cumplido, Manuel (1973): Córdoba en el siglo XV, Córdoba, Publicaciones de la Excma. Diputación Provincial de Córdoba.

Petrarca, Francesco (2008 [1366-1374]): Rerum vulgarium fragmenta, Giuseppe Savoca (ed. crít.), Firenze, Leo S. Olschki.

Real Academia Española (1984 [1726-1737]): Diccionario de Autoridades compuesto por la Academia Española, edición facsímil, Madrid, Gredos.

Recio Mateo, Luis (2005): "La catedral de Córdoba, antigua mezquita. Patrimonio de la humanidad", en La mezquita de Córdoba, Patrimonio de la humanidad, Manuel Nieto Cumplido (ed.), Granada, Edilux.

Salcedo Coronel, José García de (1644): Obras de don Luis de Góngora comentadas, Tomo segundo (Sonetos), Madrid, Diego Díaz de la Carrera.

Soria Mesa, Enrique (2013): "Góngora judeoconverso. El fin de una vieja polémica", en Begoña Capllonch, Sara Pezzini, Giulia Poggi y Jesús Ponce Cárdenas (eds.), La Edad del Genio: España e Italia en tiempos de Góngora, Pisa, Edizioni ETS, pp. 415-433.

Waissbein, Daniel (2010): "Ut sculptura poesis en Góngora", Rivista di Filologia e Letterature Ispaniche, XIII, pp. 105-142.

Waissbein, Daniel (2013): "Music and meaning in Góngora's letrilla 'No son todos ruiseñores' ", en Oliver Noble-Wood y Nigel Griffin (eds.), A Poet for All Seasons: Eight commentaries on Góngora, New York, Hispanic Seminary of Medieval Studies, pp. 153-209.

Fecha de recepción: 8 de abril de 2013

Fecha de aceptación: 20 de agosto de 2013 